\title{
Intelectualidad, habla e identidad étnica. El caso de dos intelectuales aymara de Arica y Parinacota
}

\author{
Intellectuality: spoken and ethnic identity. \\ The case of two Aymara Intellectuals from Arica and Parinacota
}

Jaime González

Universidad Diego Portales, Santiago, Chile

Recibido: 19 de diciembre de 2013. Aceptado: 10 de abril de 2014 .

Las nociones de "pueblo indígena", "etnia" y "nación" no solo pertenecen al discurso de los individuos educados y con capacidad para actuar en la esfera política pública. Son conceptos que precisan ser estáticos para afianzarse en su dominación étnica. Los otros conceptos coligados de "derecho", "cultura" y "territorio" también pretenden ser permanentes (inclusive esenciales), y en esa medida, sostener al mundo estático... (Vázquez, 1992).

\begin{abstract}
Resumen
El presente artículo busca estudiar el nexo entre formas de intelectualidad étnica y tipos de identidad étnica. Con base a esta problemática inicial, se pretende analizar los casos de dos intelectuales aymara originarios de la región de Arica y Parinacota, que presentan semejanzas y diferencias en calidad de actores. Estas mismas propiedades tendrán consecuencias en la elaboración de identidades étnicas de esta colectividad. Se sugiere como hipótesis un vínculo entre tipos de intelectuales y formas de identidad étnica en los aymara de la XV región. Con base a esta primera formulación, sostenemos que la semejanza de ambos casos explica las similitudes en la elaboración de identidad. La base

El presente artículo constituye un extracto de nuestra tesis doctoral, que se encuentra actualmente en proceso de revisión. El autor agradece tanto el apoyo económico de una beca UTA-MECESUP, como de los valiosos comentarios de la Dra. Marietta Ortega y el Dr. Daniel Poblete a esta investigación. Como siempre, las falencias del texto son de exclusiva responsabilidad de quien escribe.

** Universidad Diego Portales, Facultad de Ciencias Sociales e Historia. Santiago, Chile. Correo electrónico: jagonzag@yahoo.com
\end{abstract}


empírica del texto se apoyará principalmente en las voces de los sujetos de estudio, lo que no excluirá la alusión a notas de campo del comportamiento de estos agentes.

Palabras claves: intelectualidad, identidad étnica, conversación

\begin{abstract}
This article seeks to explore the link between forms of ethnic intellectuality and types of ethnic identity. Based on this initial problem, the paper seeks to analyze the case of two Aymara intellectuals from the regions of Arica and Parinacota, which present similarities and differences as individual actors. These same properties will have consequences in the development of ethnic identities in this community. The paper suggests a hypothesis that links the type of intellectual with form of ethnic identity in the Aymara of the XV region. Based on this first formula, we uphold that the similarity between both cases explains the similarity in the elaboration of identity. The empirical base for this text is supported mainly through the voices of the subjects of study, which does not exclude the reference to field notes on the behavior of these agents.
\end{abstract}

Keywords: intellectual, ethnic, conversation

\title{
Introducción
}

Uno de los objetos más complejos que ha abordado tanto la teoría social como la antropología, es la noción de etnicidad. La multidimensionalidad de esta nomenclatura y las dificultades de su objetivación en terreno reflejan esta condición de la acepción. Una situación semejante se observa cuando se busca establecer nexos entre esta idea y el concepto de nación. Etnia, Estado, nación y sus posibles vínculos constituyen toda una discusión científica, cuando se trata de realizar un estudio de estas características en poblaciones indígenas de Latinoamérica.

El estado del arte sobre la temática en América Latina se caracteriza por la diversidad de enfoques teóricos. El debate oscila desde posturas que privilegian conceptuar la etnicidad indígena como una propiedad abstracta (Zárate, 1993; Vargas, 1994; Tejera, 1994; De la Peña, 1995; Caudillo, 1996; Gasché, 1997a, 1997b; Sánchez, 1999; González Caqueo, 2000; Gutiérrez, 2001; Bartolomé 2002; Florescano, 2003; Zapata, 2007a), pa-

\section{Si Somos Americanos. Revista de Estudios Transfronterizos}


sando por perspectivas que analizan el objeto como una variable concreta (Wolf, 1987; Favre, 1987, 1996), hasta considerar análisis multidimensionales sobre la nomenclatura (Stavenhagen, 1992; Vázquez, 1992, 2010; Assies,1999; Sariego, 2002; Warman, 2003; González, 2006; Bengoa, 2007; Díaz Polanco, 2007). De esta discusión se desprende que la etnicidad indígena en América Latina abarca desde sus representaciones más abstractas (identidad étnica), hasta considerar colectividades concretas que se entienden dentro de un contexto material (segmentación étnica del mundo laboral; organización étnica en el campo de la política). Un aspecto no menor que se registra en esta discusión, consiste en entender la etnicidad como un movimiento político de elite, donde destaca la acción racional de una intelectualidad étnica. Para que exista un comportamiento etno-político, resulta necesario el trabajo mental de un conjunto de agentes intelectuales.

En el caso de la discusión centrada en la región andina próxima a nuestro campo de análisis, observamos una serie de semejanzas con la literatura mencionada anteriormente. Se advierten desde posturas que analizan la etnicidad abstracta en colectividades indígenas (Cancino, 2005), pasando por posturas que defienden un análisis que se finque en una epistemología del sur (Santos, 2010), hasta posturas que aborden las diversas dimensiones de la etnicidad (Albó, 2000 y 2005). Este hecho también es observable en la discusión bibliográfica de nuestro campo analítico. Para el caso de Arica y Parinacota $-\mathrm{y}$ Tarapacá se aprecian desde perspectivas que privilegian el estudio de la etnicidad abstracta (Van Kessell, 1980; García, 1997; Zapata, 2007b), pasando por análisis que privilegian el estudio de la etnicidad concreta (Grebe, 1997; Hopenhayn, 2006), hasta ópticas que consideran las múltiples dimensiones de esta propiedad (González, 1998, 2000; Gundermann, 2001, 2003a, 2003b, 2003c; Gundermann y Vergara, 2009; Poblete, 2010; Morales y González, 2011).

Por un rumbo semejante a las perspectivas abstractas y multidimensionales de la etnicidad, consideramos el estudio de esta en calidad de propiedad ideológica o abstracta, es decir, como identidad étnica. Abordamos nuestro objeto como un producto del trabajo racional de intelectuales étnicos. En función de ello, nos apoyamos en una ruta crítica, que considera la etnicidad desde la línea teórica generada por Max Weber (2002), Abner Cohen (1969), Frédrik Barth (1972) y Sinisa Malesevic (2004). Complementamos el análisis de la identidad étnica, en función del concepto de identidad colectiva formulado por Amartya Sen (2008), ya que su noción resulta de utilidad, al considerar esta propiedad según la dicotomía identidad plural/identidad singular. En base a esta antinomia, el autor nos proporciona un marco teórico útil para distinguir formas de identidad colectiva, sobre todo las que están vinculadas con la política contingente. En relación al concepto de intelectualidad, consideramos los aportes de Isaiah Berlin (1968), Michael Löwy (1979) y 
Ernest Gellner (1998), ya que nos permiten analizar a los sujetos con base a un concepto que caracterice a los intelectuales como sujetos situados en una dimensión abstracta de la sociedad. Esta dimensión se conforma por un universo de valores cualitativos, que genera consecuencias en los modos de razonar de estos agentes, incluyendo en este aspecto una serie de tensiones personales que sufren estos individuos, en relación tanto a la epistemología en la que se apoyan, como en las múltiples filiaciones colectivas que poseen. Este ámbito cultural descrito genera consecuencias en el intelecto de estos agentes, efectos tales como la gestación de sujetos dedicados por y para el conocimiento (caracterizados como intelectuales), pasando por agentes administradores de cultura (caracterizados como administradores culturales), hasta generar comportamientos carismáticos donde se combine ciencia con una profunda conciencia moral (caracterizados como intelligentsia). Según este marco de referencia, ocuparemos las nociones de administrador cultural (Löwy, 1979) e intelectual (Berlin, 1968), más el concepto de dilema de Habsburgo (Gellner, 1998), en calidad de tensión de conciencia e identidad en sujetos intelectuales.

El presente artículo busca estudiar el vínculo entre formas de intelectualidad étnica y tipos de identidad étnica, en el caso de dos intelectuales aymara originarios de la $\mathrm{XV}$ región. Ambos sujetos presentan semejanzas y diferencias tanto en sus características como agentes, como en su comportamiento hablado sobre la identidad de su etnia. Se sugiere como hipótesis un vínculo causal entre tipos de intelectuales y formas de identidad étnica en los aymara. Con base a esta primera formulación, sostenemos que la semejanza de ambos casos explica las similitudes en la elaboración de identidad.

En el plano de la metodología de registro y análisis de los datos, nos apoyamos tanto en la teoría de la estructuración (Giddens, 2003), como en el análisis de la conversación (Moerman, 1991; Coulón, 1998). De la primera consideramos el principio de doble hermenéutica, ya que permite analizar el comportamiento hablado de estos sujetos, considerando la situación dialógica en que se genera el habla de estos agentes. El segundo procedimiento es de utilidad, debido al análisis de los actos de habla en el contexto de una conversación cotidiana (en este caso, en una entrevista semiestructurada). De esta manera, el estudio de las identidades étnicas estará centrado en las voces de los sujetos de estudio en calidad de comportamiento hablado.

La carne de este relato serán las voces de dos sujetos aymara que participaron en la construcción de una organización étnica, y en una serie de acciones políticas dedicadas a la lucha por el reconocimiento étnico y nacional. Los datos son resultado de un trabajo de campo en la región de Arica y Parinacota, realizado entre enero-marzo del año 2010. En ese tiempo, los sujetos de estudio formaban parte de la administración pública local y 
regional (Municipalidad de Arica; CONADI, Arica). En cuanto a los contenidos de este artículo, consideramos un primer apartado que aborda el caso de Alfredo, sujeto que en el período de estudio formaba parte de CONADI. Un segundo capítulo considera el caso de Santiago ${ }^{1}$, agente aymara que en el mismo período laboraba en la Municipalidad de Arica.

\section{Administración cultural e identidad étnica: el caso de Alfredo}

Al momento de conocer a Alfredo en las oficinas de CONADI-Arica, él se identificó como un aplicador o administrador más que como un intelectual. Su autoadscripción nos resultó sugerente, tomando en cuenta que nuestro marco teórico de intelectualidad étnica consideraba el concepto de "administrador cultural", acepción tributaria de Michael Löwy (1979). No obstante esta primera presentación, observamos en Alfredo a un sujeto con altas competencias intelectuales y un pasado político-ideológico altamente productivo. Su propio testimonio revela su papel como intelectual orgánico en una asociación étnica conocida como el Pacha Aru². De esta trayectoria política y académica se explica el discurso de identidad étnica que vamos a describir.

La temática sobre la identidad étnica y nacional ha sido ampliamente desarrollada por el informante. Cuando conversamos sobre esta en relación al mundo aymara, sostuvo:

Mira, creo que la identidad aymara ha ido creciendo sustancialmente. Inicialmente de un proceso que partió a principios de la década del 80', en nuestra zona norte. Yo diría que nadie sabía que existía una identidad aymara. Partiendo por el concepto de pueblo. Si tú retrocedes en el tiempo, a fines del 70', principios de los 80 ', y hablabas sobre la existencia de un pueblo aymara, yo te diría que nadie de los propios aymara se reconocía como tales. No tenían el concepto de ser parte de un pueblo llamado aymara. A lo mucho, sabían que algunas personas indígenas de esta zona hablaban el idioma aymara. Pero desconocían ser parte de un pueblo aymara. Eso como primer principio. Por lo tanto, partiendo de ese primer principio, te diría que la identidad aymara ha crecido pero sustancialmente. En términos cuantitativos, y en términos cualitativos...

\footnotetext{
Por razones de ética profesional, optamos por modificar los nombres originales de los informantes con pseudónimos. Omitimos los cargos que ocupaban debido a los mismos motivos. Las dependencias de labor corresponden a la realidad de los sujetos de estudio.

2 Organización étnica nacida en la década de los años 80 en la Región de Arica y Parinacota. Para profundizar en esta información, ver Gundermann y Vergara (2009).
} 
Luego agrega:

...Si tú comparas el Censo del año 92, en nuestra región se identificaron un promedio de quince mil personas de ascendencia aymara. Estoy hablando hace veinte años atrás. Y el 2002, en nuestra Región Arica-Parinacota, solamente subió a veinticinco mil aymaras. O sea, casi duplicamos. Y si se suma Arica-Parinacota más Tarapacá, esto sube a cuarenta mil aymaras. En diez años, de quince mil a cuarenta mil. O sea, se duplicó. $\mathrm{Y}$ aun así, considero que falta mucho por el tema identidad. ¿Por qué razón? Porque en nuestras regiones de Arica y Parinacota y Tarapacá, debiera estar bordeando una población más allá de las cien mil personas. Yo diría que nosotros como zona norte, Arica-Parinacota más Tarapacá, debiéramos estar bordeando las quinientas mil personas, más menos. Y esta población debiera ser, por lo menos, un tercio de descendencia aymara. O sea, estamos hablando por lo menos de una cifra cercana a las doscientas mil personas de ascendencia indígena. Pero el Censo de casi diez años atrás, nos dice que se identificaron cuarenta mil personas de origen aymara. Porque a nivel nacional, arrojó una población de cuarenta y ocho mil quinientas personas de origen aymara, a nivel nacional. Pero cuarenta mil se identificaron acá, en la zona norte de Arica y Parinacota y Tarapacá. Entonces, cuantitativamente hemos crecido. Pero aun así está lejos de la realidad.

El testimonio de Alfredo revela una interesante visión cuantitativa - una identidad numérica según Hoffsaes y Vitalis (1995) - sobre el fenómeno. La identidad aymara se ligaría en un principio a la lengua. Sin embargo, la identificación implicaba una problemática. Los censos de 1992 y de 2002 constituyen, a juicio de este informante, un ascenso en el plano de la identificación. Su conciencia discursiva revela implícitamente cómo esta identidad implica invención, hecho que nos llevaría a entender que Alfredo analiza la identidad étnica como una propiedad singular. Vincular la identidad étnica a la lengua y el anhelo que esta propiedad pueda extenderse, revela una tendencia en este comportamiento hablado a la defensa de una identidad singular.

Alfredo manifiesta claramente que se debe trabajar en el crecimiento de la identidad aymara. Al momento de entregar su visión sobre el tema, facilita inconscientemente las variables explicativas del crecimiento cuantitativo de esta identidad. Debido a las características del testimonio, nos vemos en la necesidad de reproducir la totalidad de este, solo con pequeñas interrupciones nuestras por motivos de exposición. Según su testimonio:

\section{Si Somos Americanos. Revista de Estudios Transfronterizos}


Por lo tanto, queda bastante por trabajar, pero hemos ido creciendo en esto. Creo que un elemento importante que ayudó en este proceso de identidad post nacimiento de la Ley Indígena, ha sido, sin duda, la creación de nuestra institución: la CONADI. Para ser más específico, en el caso de nuestra ciudad, la emergencia de una radio emisora que marcó identidad: la Radio Andina. Yo diría, hoy en día, que sus auditores son el noventa y tanto por ciento gente de origen aymara. Por lo tanto, es una radio cuyo segmento cautivo es la gente indígena. A tal punto que la Radio Andina -que surgió hace unos doce años atrás - es la única radio en Arica, donde tocan música típica del mundo andino. Tocan música chicha, música cumbiera, pero de corte andino. Hoy en día, ha entrado a casi la mayoría de las radios por un tema comercial. Pero la Radio Andina fue la que impuso y le creó el espacio al mundo indígena. A tal punto que en Perú y Bolivia, que son países con alta población y creatividad en música indígena, no tenían una radio de este estilo. Cuando salió la Radio Andina, muchas radios cambiaron su estilo en Perú. Fue así como colocaron música tradicional indígena.

Luego sostiene:

Y la respuesta básica para mí, es que el tema del estereotipo, la pobreza de ver el mundo indígena con su música, era considerado algo no apropiado para transmitirlo. Por lo tanto, las radios simplemente no lo usaban. El indígena en ese lado, por ser mayoría, lo practicaba en forma cotidiana. En sus fiestas, en todo. Acá en Arica, la gente indígena - antes que emergiera la Radio Andina - todo lo hacía en forma solapada en sus casas. Jamás en forma pública. Salió la Radio Andina, y al poco tiempo vemos fiestas, en las casas o en los centros que se arriendan, con música chicha. Por un lado, la CONADI reforzando el tema de la identidad. Creando espacios para que el mundo indígena se autoreconozca. Porque también muchos se autoreconocen por un tema de recursos. Por ejemplo, los alumnos becarios. Nosotros acá tenemos la prueba fehaciente que muchos alumnos obtuvieron la acreditación que eres indígena, porque los papás les vinieron a sacarles. No porque ellos se sintieran identificados como indígenas. Te estoy hablando de jóvenes universitarios, que los papás venían a sacarle, por un tema de que había posibilidades de obtener un subsidio ¿te das cuenta? Sin embargo, muchos en ese proceso fueron asumiendo su identidad. Y la prueba más eficiente es que en todas las universidades hay centros o grupos organizados de estudiantes indígenas. La Tarapacá tiene la Asociación de Estudiantes de Pueblos Originarios, como la más fuerte que agrupa a los indígenas. Esta ha logrado, inclusive, atraer proyectos para trabajar con los cabros al interior de la misma universidad ¿te das cuenta?...

Por último, llega a afirmar que: 
Entonces, la identidad ha ido creciendo, potenciándose. Por ejemplo, a nivel urbano tenemos dos ligas deportivas fuertes, de carácter indígena. Estas también trastocan un tema de nacionalidad, aunque tú no lo creas. Nosotros tenemos la ASFA, que es la Asociación de Fútbol Andino. Esta liga, está constituida por gente migrante de los pueblos de la precordillera. Por lo tanto, los nombres de los mismos equipos de fútbol, te van a hacer referencia al pueblo. Está la liga Andino de Belén, Estrella de Putre, etc. En el fondo, son gente migrante de esas localidades. Aymaras con acento histórico en estos territorios del norte de Chile. Como ellos dicen, "nosotros somos chilenos". Y tenemos otra liga deportiva rural. Cuyas canchas las tienen a la entrada de Arica. Es fuerte y potente. Está constituida, fundamentalmente, por jugadores de ascendencia boliviana indígena ¿te das cuenta? La pregunta es ¿por qué no están unidos, si son indígenas? Porque todavía hay acá, un estereotipo de este aymara que se dice histórico de esta zona, y que se siente más chileno que el poroto. Y que reclama soberanía, y tenencia de tierras de muchas generaciones acá en el norte de Chile. Por lo tanto, no se mezcla mucho con la gente migrante de Bolivia, porque para ellos son afuerinos y no son chilenos. A pesar de que la mayoría de ellos son hijos de extranjeros, o nietos de extranjeros. Entonces, ahí hay una separación. Y porque también culturalmente, si bien son de la cultura aymara, existe una diferencia de idiosincrasia entre el aymara chileno y el aymara boliviano. Eso hizo que se viviera este divorcio, y existan hoy día dos ligas potentes. Pero hay niveles de identidad, sin duda, hay niveles de identidad.

El testimonio de Alfredo es revelador en el plano de la identidad colectiva. Por una parte, se observan dos organizaciones que explican la etnogénesis andina. Por otra, se aprecia la acción racional de agentes individuales, que instrumentan la etiqueta amerindia para obtener regalías del sistema. Por último, se encuentran los niveles de identidad étnica según la sede local. Por tanto, el espacio físico, el comportamiento individual interesado y el poder organizado explicarían esta reetnificación aymara.

Sin duda, es plausible pensar que la identidad plural de los agentes andinos sufrió un gradual proceso de mutilación por la acción política. Se observa en el Estado, a través de CONADI y sus prebendas expresadas en becas. Se aprecia en la Radio Andina, en calidad de organización ideológica. Llama la atención también cómo este discurso de identidad étnica aborda la fragmentación étnica debido a la acción de los Estados nacionales. Los aymara pueden ser chilenos o bolivianos, lo que genera procesos de interacción interétnica entre colectividades andinas de ambos lados de la cordillera. Por tanto, el habla de nuestro informante se encuentra situado en un contexto propio de la geopolítica sudamericana.

160 Si Somos Americanos. Revista de Estudios Transfronterizos 
Alfredo sostiene que otra variable para fortalecer la identidad aymara ha sido la educación intercultural bilingüe. Si bien es un proceso que lleva menor tiempo en la zona, se han hecho esfuerzos al respecto. La idea es llevar la identidad a las escuelas de la región, haciendo hincapié en los establecimientos rurales. Incluso en estos establecimientos se celebra el año nuevo aymara. Quizás lo más relevante de este testimonio radica en lo que Alfredo definía como niveles de identidad aymara. Según este informante, los agentes se diferencian según la sede física:

Existen diferencias en la identidad ¿por qué razón? Porque la gente del interior —si bien hoy en día se identifican como aymara, o perteneciente a la cultura aymara o quechua - son más localistas. Tienen una identidad de comunidad. Entonces, si tú le preguntas a cualquier individuo de la comunidad, ellos hablan más como de la localidad. Si es de Putre, habla y se siente como putreño. Se siente agricultor. Si lo quieres mezclar con el aymara del altiplano, al tiro él te dice que no. Ellos dicen "no me mezcles con ellos, yo no soy ganadero". Lo mismo el del altiplano. Entonces, ellos se separan por actividad económica. Unos son agricultores. Otros son ganaderos. Y lo que los une es el tema de la identidad localista. A diferencia del aymara más intelectualizado, o con mayor conciencia de identidad, que pregona más por el concepto de Pueblo y por la proyección como Pueblo. El aymara de comunidad se va a centrar en su lucha cotidiana: el diario vivir y las posibilidades de desarrollo de su comunidad. No te va a hablar por el Pueblo aymara. Él no va a decir "mira, nosotros los aymara". No. Te va a decir "mi localidad, tiene estos problemas". Y es lógico entenderlo, porque es lo que él quiere. O sea, él busca algo mejor para él y su familia y donde vive. No les interesa el resto. No tienen la mirada global...

Luego, agrega:

Y esa mirada, sin duda, la tiene la gente que vive en el mundo urbano y, sobre todo, la gente más intelectualizada. Nosotros vemos el tema global. No un tema de apoyo local, sino un tema de Pueblo. Y si nosotros logramos entablar una vía de desarrollo para el Pueblo, entonces se desarrollan todas las comunidades. Porque existe una viabilidad cierta. Por eso estamos creando los famosos Consejos de las Áreas de Desarrollo Indígena. Esto sería con participación de la dirigencia de los pueblos, para que ellos se empoderen de este proceso de participación. Para que ellos hagan propuestas a los servicios públicos, a los directores, a los jefes de servicio. Para que, en conjunto, vayan pensando una política de desarrollo para el Pueblo, y no para la localidad. No debemos segmentarnos. Y eso es lo que nos pasa generalmente con la dirigencia local. Porque ellos luchan por el tema local. El Programa Orígenes, que está hace unos ocho años 
introducido en la región, era el caballito de batalla del Estado chileno para sacar del estancamiento económico a la población aymara. Y ha tenido ese problema, porque el Programa Orígenes tiene que planificar una política de desarrollo integral. Pero como se abrieron las puertas de participación a las comunidades, las comunidades ven el área chica de su comunidad. No ven el desarrollo macro. Entonces, ellos compiten. Como no alcanza para todos, se dan duro, porque cada uno quiere llevarse su tajada. Entonces, el programa, para tranquilizar, empieza a cortar la torta por trocitos. Y todos quedan contentos...

Por último, afirma:

Pero ese elemento de focalización de recursos, no te permite gerenciar un desarrollo de esa comunidad. Porque lo que le diste es muy pequeño. Entonces, se diluye la posibilidad de gerenciar y generar un verdadero desarrollo. Porque el desarrollo se tiene que hacer con una planificación macro para todos. No puedes hacerlo focalizando la totalidad en pequeños montos. Esas son migajas. Eso sirve solo para tranquilizarlos. Con eso no se genera desarrollo. El desarrollo es el conjunto. El Programa Orígenes debiera estar coordinado con la inversión que hacemos nosotros como CONADI. Debiera estar coordinado con las acciones que hace el gobierno local, el municipio. Debiera estar coordinado con las posibles inyecciones de plata que haga el gobierno regional. O sea, la suma de todo eso nos hace posible generar un desarrollo. Pero si no logramos eso, seguimos repartiendo migajas y al que le cae, bien. Pero no avanzamos. $\mathrm{Y}$ ese es uno de los grandes problemas, a mi juicio, en esta estrategia de planificación. Difícil, porque sale un tema político. Que "tú eres de la DC. El otro es del PC." La lucha político partidaria limita. Así es el tema.

El testimonio de Alfredo analiza la identidad colectiva embonada con la política nacional y regional. En función de ello, intervienen variables propias de la política local de los pueblos del interior, más la acción política de los partidos en este proceso. Frente a ello, la intelectualidad aymara defiende el interés global de la etnia, independiente que los actores parroquiales no observen este hecho. En este sentido, el testimonio de Alfredo se inclina por una identidad singular para comprender el mundo indígena regional, lo que no impide a este intelectual considerar las dimensiones plurales en los aymara.

Si bien Alfredo demuestra un alto desarrollo en sus actos de habla - lo que se observa en la gran coherencia de su testimonio sobre la identidad étnica- no es posible explicar este hecho sin la situación indexical en que se genera este comportamiento hablado. El testimonio es resultado de la conversación sostenida entre Alfredo y nosotros.

\section{Si Somos Americanos. Revista de Estudios Transfronterizos}


La entrevista se realizó en las oficinas de CONADI-Arica, lugar donde nuestro informante se encontraba cómodo por ser su espacio laboral. En esta plática no se dieron mayores interrupciones, y el diálogo se desarrolló con amenidad. En cuanto a la riqueza conceptual del sujeto y su coherente discurso, el hecho se explica - entre otros factorespor la información social que disponía Alfredo sobre nosotros. Siendo presentado ante él por una informante clave con quien compartía una amistad de años, este sujeto tuvo oportunidad de obtener datos útiles para saber cómo comportarse en público en relación a nosotros. Toda conversación implica una relación intersubjetiva, donde la situación de copresencia se caracteriza por un principio de doble hermenéutica. Según el modo como los agentes interpretan al "otro", generan su comportamiento - actuado o hablado- en relación a estos. La situación no resulta distinta en un contexto social de entrevista, hecho que será nuevamente observable en el siguiente apartado.

\section{Intelectualidad indianista e identidad étnica: el caso de Santiago}

Cuando conocimos a Santiago, él se presentó como un intelectual indianista del mundo aymara. Al igual que Alfredo, en su juventud militó en el mencionado Pacha Aru. Su discurso fue sugerente, tomando en cuenta que nuestro marco teórico considera una dimensión de estas características, tributario del aporte de Isaiah Berlin (1968). El testimonio de Santiago es altamente sofisticado. Su discurso revela un intelecto cultivado y cosmopolita. Cuenta con una formación académica diversa y de elite. Una suma de alta instrucción con experiencia vivida es lo que resume a este agente. Se trata de un comportamiento hablado característico de un sujeto intelectual dedicado por y para el conocimiento, generador de productos ideológicos para su causa política.

Santiago refleja una inteligencia viva y conceptual en todos los ámbitos abordados de su discurso de identidad étnica. Este hecho es bastante claro cuando se trata de comparar la identidad aymara con la identidad chilena. Según su testimonio:

Ahí es más complejo, porque tenemos dos modelos. Los pueblos indígenas son más colectivos. Más hermanados con la protección de los recursos naturales, donde su eje central es el territorio. Es cómo vamos fortaleciendo nuestra propia identidad cultural. Por otra parte, está el modelo nacional. Si tú miras a este último, tiene poco de eso. De hecho, a nosotros nos ha costado mucho instalar en el Ministerio de Educación una unidad de pueblos indígenas. La unidad de Educación Intercultural Bilingüe es uno de los ejes que deberían potenciarse a nivel nacional. Pero ahí entra la colisión con el 
concepto de Estado-Nación. De un país unitario y homogéneo. Una identidad única. Este modelo colisiona con el concepto de pueblos indígenas, que cuenta con una mirada diferenciada. Esta mirada más diversa le asigna el valor que tiene cada pueblo. Ahí tenemos una colisión conceptual. Esta se da entre los intelectuales que generan los programas y están en la dirección de este país, versus la propuesta indígena de una educación bilingüe intercultural...

El testimonio de Santiago revela una disyunción conceptual: se trata de la antinomia identidad indígena/identidad nacional. La primera se caracteriza por ser colectiva y plural. Valora el equilibrio entre la humanidad y su medioambiente. La segunda, en cambio, se distingue por lo contrario. Se trata de una identidad individualista y singular. Vive en un constante desequilibrio con el medioambiente. Desprecia las culturas subalternas, sobre todo si tienen raíz indígena. Abraza la cultura occidental y el unitarismo político.

Se trata de un discurso esencialista sobre las identidades colectivas, a lo que suma una alta capacidad de observación. En este sentido, la identidad étnica aymara se entenderá desde esta perspectiva, llegando a sostener que:

La identidad, tiene algo muy de personal también. Esto, de acuerdo a tu contexto o tus vivencias. En lo local, creo que la identidad se ha ido fortaleciendo. Ha tenido líneas de encuentro comunes. Por ejemplo, el hecho de que hayamos tenido un carnaval acá, te marca una identidad. Ahí todos bailan. Pienso que el 80 o 90\% de la población aymara de la región, está involucrada con su identidad. Cada vez son menos los aymaras que niegan su identidad. Creo que eso es una gran cosa. Pero también hay niveles de identidad. Por ejemplo, en la cultura aymara existen generaciones que sufrieron más que otras. El adulto mayor vivió la época de la chilenización, cuando se hincaban ante la bandera chilena. Sufrieron una vejación de ese tipo. Obviamente, ellos tienen una identidad con traumas duros. Ahora, los hijos de esa generación que vieron que humillaron al papá, ante esa situación ¿qué es lo que quieren? Que sus hijos no sufran lo mismo. Esa es la respuesta natural de la violencia ejercida. Esa generación intermedia, que oscila entre los 50 y los 60 años, tomó el camino de la desaymarización. Y la gente está volviendo a su identidad. A algunos les cuesta volver...

Luego, agrega:

Pero la generación de 50 años para abajo ya acepta su identidad. Ahora, los contextos han sido favorables. El hecho de que haya una Ley Indígena. Que exista una beca indígena. Que se hayan generado políticas públicas al respecto. Se ha generado un

\section{Si Somos Americanos. Revista de Estudios Transfronterizos}


contexto tremendamente favorable para la identidad. Entonces, yo creo que la identidad, por lo menos en la provincia de Parinacota, ha ido evolucionando para mejor. De hecho, cuando se hace el carnaval, tenemos gente de todo tipo. Entonces, también hay que entender que la identidad aymara va trastocando la identidad regional. De hecho, el plan de desarrollo regional, cuenta con varias líneas que apuntan a la identidad. Una de las identidades que hay que fortalecer es la de los pueblos indígenas de la región. Esta constituye un valor para el desarrollo de la región. Ahora, lo que falta es el tema de contenidos. Yo creo que ya salimos del tema "¿somos indígenas o somos aymaras?". Lo que debemos responder ahora es ¿qué es ser aymara? Debemos recuperar nuestro idioma y nuestra espiritualidad. El siguiente paso sería trabajar la identidad en nuestro territorio. Eso no implica que abandones la interculturalidad. El dominio del castellano y otras lenguas que te permitan ser ciudadano del mundo. Con esa herramienta, el futuro líder o profesional aymara, va a poder defender mejor su condición de tal. Mientras tengamos territorio, idioma, espiritualidad, vamos a seguir...

El testimonio de Santiago revela la complejidad de la identidad aymara. Existe tanto una dimensión individual como una colectiva. Sin embargo, también se observa una identidad generacional. La generación que vivió el proceso de chilenización sufrió la imposición de una identidad ajena, mientras que la generación posterior optó por chilenizarse para evitar sufrir los traumas psicológicos de sus antecesores. La tercera generación retornó a su identidad original. Este último hecho ha sido facilitado por las habilitaciones de la estructura. En este sentido, el testimonio de Santiago analiza la conflictiva convivencia entre una identidad singular - la identidad nacional- y una identidad plural (en este caso, el mundo aymara).

Por otro lado, la XV región pareciera estar viviendo en el presente un proceso inverso, donde la identidad aymara ha logrado identificar a Arica y Parinacota. Según Santiago, considerando esta realidad actual, se deben seguir los siguientes pasos: a) recuperar la lengua aymara; b) reconstruir la cultura de la etnia y c) posteriormente, desarrollar todo esto en su territorio. Esto sin descuidar el dominio de otras lenguas y conocimientos. El objetivo radica en enfrentar los desafíos del futuro con competencias identitarias y técnicas. En este sentido, nuestro informante combina propiedades singulares y plurales para construir un concepto de identidad aymara. Al igual que Alfredo, se observa una convivencia de ambas variables en el comportamiento hablado de este intelectual indígena.

Si bien Santiago demuestra un alto desarrollo en sus actos de habla - lo que se observa en la gran coherencia de su testimonio sobre la identidad étnica- nuevamente 
no es posible explicar este hecho sin la situación indexical en que se genera este comportamiento hablado. El testimonio es resultado de la conversación sostenida entre nosotros. La entrevista se realizó en las oficinas de la Municipalidad de Arica, lugar donde nuestro informante se encontraba cómodo por ser su espacio laboral. En esta plática no se dieron mayores interrupciones, y el diálogo se desarrolló con amenidad aunque con una postura de autoridad académica frente a nosotros. En cuanto a la riqueza conceptual del sujeto y su coherente discurso, el hecho se explica - entre otros factores- por la información social que disponía Santiago sobre nosotros. Tomando en cuenta que nos presentamos ante él como estudiante tesista en Antropología, Santiago tuvo oportunidad de obtener datos útiles para saber cómo comportarse en público en relación a nosotros. Como dijimos anteriormente, toda conversación implica una relación intersubjetiva, donde la situación de copresencia se caracteriza por un principio de doble hermenéutica. Según el modo como los agentes interpretan al "otro", generan su comportamiento - actuado o hablado- en relación a estos. La situación no resulta distinta en un contexto social de entrevista, hecho que es evidente cuando un sujeto cumple el papel de autoridad intelectual frente a otro que cumple el papel de escucha.

\section{Conclusiones}

A lo largo de este artículo se observaron los discursos de identidad étnica de dos intelectuales aymara. Los testimonios registrados fueron ocupados como argumentos empíricos para verificar nuestra hipótesis de trabajo. Con base a ello, se pueden establecer cuatro conclusiones.

Una primera conclusión de este estudio es que el discurso de identidad étnica aymara es consecuencia de agentes altamente escolarizados. Todo comportamiento hablado de las características mencionadas implica el dominio de un discurso experto. Para que se genere este acto de habla, resulta fundamental una alta instrucción. Con base a lo planteado por Michael Löwy (1979), sabemos que esta característica es propia de intelectuales. La división del trabajo y la estratificación social conducen a la formación de sujetos con estos atributos. El discurso de identidad étnica —en calidad de generador de identidades singulares - constituye un producto del habla de expertos.

Una segunda conclusión tiene que ver con el comportamiento hablado mismo. Los actos de habla registrados reflejan tanto un análisis regional, como una dicotomía conceptual entre culturas. El primer aspecto hace alusión tanto a la identidad aymara, como a los niveles de identidad de esta. Si bien los aymara constituyen una sola colecti- 
vidad étnica, esta se encuentra fragmentada por una diversidad de factores políticos. El segundo aspecto hace hincapié en la antinomia entre cultura indígena y cultura chilena. Esta última tiene efectos devastadores en el plano de la identidad. Mientras las colectividades amerindias son armónicas con la naturaleza y tienden hacia la cohesión comunitaria, la chilenidad se caracteriza por su desdén hacia el medio ambiente y su tendencia hacia el individualismo. Mientras el primer aspecto revela una alta capacidad de análisis crítico, el segundo entrega una visión primordialista sobre la realidad.

Una tercera conclusión apunta al terreno de la identidad. Los testimonios registrados privilegian la dimensión singular de la identidad colectiva. No obstante, pareciera ser que el sujeto individual no tiene capacidad de elegir. Tanto Alfredo como Santiago hablaron de la identidad aymara como una entidad colectiva. Si bien se generó un primer registro que menciona la dimensión individual de nuestro objeto, los informantes privilegiaron el ámbito colectivo de este. Todo parece indicar que este hecho es consecuencia del pasado político de los sujetos de estudio.

Una última conclusión, que apunta directamente a nuestra hipótesis de trabajo, sostiene que las semejanzas en los actos de habla se explican por los similares atributos que presentan ambos agentes. El hecho de que Alfredo tienda hacia la administración cultural, mientras Santiago tienda hacia la intelectualidad, implica que, a pesar de sus diferencias, ambos agentes se dedican al trabajo cultural y cuentan con competencias intelectivas semejantes. A esto se suma un pasado político y una socialización intelectual común. Ambos provienen del mismo universo de valores cualitativo. Las contradicciones discursivas se entienden en el contexto conflictivo entre la epistemología en que fincaron sus mentes, y la contingencia cultural y política vivida en la XV región. Frente a condiciones intelectivas semejantes, se pueden observar actos de habla semejantes. Las diferencias en sus testimonios se pueden explicar tanto por la historia de vida de los agentes, como por la situación indexical en donde generan sus discursos.

Una investigación pendiente para nosotros será establecer un contraste necesario entre este discurso y los actos de habla propios de agentes legos. Nuestros informantes mencionaron la visión de estos sujetos a lo largo de la entrevista. Consideramos necesario conocer este tipo de discursos a futuro. Solo de esta manera se podrá fortalecer una hipótesis que sostenga que el discurso de identidad étnica entre los aymara de Arica y Parinacota, es consecuencia del comportamiento hablado de una intelectualidad étnica. 


\section{Referencias}

Assies, W. (1999). Pueblos indígenas y reforma del Estado en América Latina. En W. Assies, G. Van der Haar y A. Hoekema (eds.), El reto de la diversidad (pp.1-16). Michoacán, México: El Colegio de Michoacán.

Albo, X. (2000). Aymaras entre Bolivia, Perú y Chile. Estudios Atacameños 19, 43-73.

Albo, X. (2005). Alcaldes y munícipes indígenas en Bolivia 2002. La Paz, Bolivia: CIPCA.

Bengoa, J. (2007). La emergencia indígena en América Latina. Santiago, Chile: Fondo de Cultura Económica.

Barth, F. (1972). Los grupos étnicos y sus fronteras. México: Fondo de Cultura Económica.

Bartolomé, M. (2002). Movimientos indios en América Latina. Los nuevos procesos de construcción nacionalitaria. Revista Desacatos 10, 148-166.

Berlin, I. (1968). The Power of Ideas. Princeton, New Jersey, US: Princeton University Press.

Cohen, A. (1969). Custom and politics in urban Africa. Berkeley, California: University of California Press.

Coulon, A. (1998). La etnometodología. Madrid, España: Cátedra.

Caudillo, G. (1996). Cultura India y Sociedad Nacional: México, Bolivia y Perú. Guadalajara, México: Cuadernos del Cucsh-Universidad de Guadalajara.

Cancino, H. (2005). Indianismo, Modernidad y Globalización. Revista Sociedad y Discurso 8.

De la Peña, G. (1995). La ciudadanía étnica y la construcción de los indios en el México contemporáneo. Revista Internacional de Filosofía Política 6, 116-140.

Díaz Polanco, H. (2007). Elogio de la diversidad. Globalización, multiculturalismo y etnofagia. México: Siglo XXI.

Favre, H. (1987). El Estado y el campesinado en Mesoamérica y los Andes. En S. Glantz (comp.), La heterodoxia recuperada. En torno a Ángel Palerm (pp. 427-460). México: Fondo de Cultura Económica.

168 Si Somos Americanos. Revista de Estudios Transfronterizos 
Favre, H. (1996). El indigenismo. México: Fondo de Cultura Económica.

Florescano, E. (2003). Etnia, Estado y Nación. México: Taurus.

Giddens, A. (2003). La constitución de la Sociedad: bases para la teoría de la estructuración. Buenos Aires, Argentina: Amorrortu.

Gasché, J. (1997a). Educación intercultural vista desde la amazonia peruana. En M. Bertely y A. Robles Valle (coord.), Indígenas en la escuela (pp. 147-158). México: Consejo Mexicano de Investigación Educativa.

Gasché, J. (1997b). Más allá de la cultura: lo político. Teoría y práctica en un programa de formación de maestros indígenas amazónicos de Perú. En M. Bertely y A. Robles Valle (coord.), Indígenas en la escuela (pp. 219-244). México: Consejo Mexicano de Investigación Educativa.

Gellner, E. (1998). Language and Solitude. Wittgenstein, Malinowski and the Habsburg Dilema. Cambridge, UK: Cambridge University Press.

Gutiérrez, N. (2001). Mitos nacionalistas e identidades étnicas: los intelectuales indígenas y el Estado mexicano. México: Consejo Nacional para la Cultura y Artes, Instituto de Investigaciones Sociales, Editorial Plaza y Valdés.

García, B. (1997). El discurso político de las organizaciones aymaras del norte de Chile. Tesis de doctorado, Universidad Complutense de Madrid, Madrid, España.

Grebe, M. E. (1997). Procesos Migratorios, Identidad Étnica y Estrategias Adaptativas en las Culturas Indígenas de Chile: Una Perspectiva Preliminar. Revista Ethno 1. Versión electrónica. Facultad de Ciencias Sociales, Universidad de Chile. Santiago de Chile.

González, H. (1998). Apuntes sobre el tema de la Identidad Cultural en la Región de Tarapacá. Estudios atacameños 13, 27-45.

González, H.(2000). Identidad cultural aymara, nacionalidad y globalización. En ¿Hay patria que defender? La identidad nacional frente a la globalización (pp. 263-275). Santiago, Chile: Centro de Estudios para el Desarrollo. 
González Caqueo, J. M. (2000). Líderes profesionistas y organizaciones étnicas-sociales. Rastros y rostros en la construcción de la p’urhepecheidad en Paracho. Tesis de maestría, CIESAS-Unidad Occidente, México.

González, J. (2006). Estado nacional en México, etnicidad indígena e identidad étnica: el caso de los intelectuales purhépechas. Cuadernos Interculturales 6, 55-92.

Gundermann, H. (2001). Procesos regionales y poblaciones indígenas en el norte de Chile. Un esquema de análisis con base en la continuidad y los cambios de la comunidad andina. Estudios Atacameños 21, 89-112.

Gundermann, H. (2003a). Las poblaciones indígenas andinas de Chile y la experiencia de la ciudadanía. En H. Gundermann, R. Foerster y J.I. Vergara (eds.), Mapuches y Aymaras. El debate en torno al reconocimiento y los derechos ciudadanos (pp. 19-104). Santiago, Chile: Universidad de Chile, Programa de Estudios Desarrollo y Sociedad, RIL Editores.

Gundermann, H. (2003b). La formación del espacio andino en Arica y Tarapacá. Revista de Historia Indígena 7, 87-138.

Gundermann, H. (2003c). Sociedades indígenas, municipio y etnicidad: la transformación de los espacios políticos locales andinos en Chile. Estudios Atacameños 25, 55-77.

Gundermann, H., y Vergara. J. I. (2009). Comunidad, organización y complejidad social andinas en el norte de Chile. Estudios Atacameños 38, 107-126.

Hopenhayn, M., Bello, Á., y Miranda, F. (2006). Los pueblos indígenas y afro descendientes ante el nuevo milenio. CEPAL. Serie Políticas Sociales, 18. Naciones Unidas. Santiago de Chile.

Hoffsaes, C., y Vitalis, A. (1995). Los hombres-número. Mundo científico 161, 876-879.

Löwy, M. (1979). Para uma sociologia dos intelectuais revolucionários. A evolucao política de Lucács (1909-1929). Sao Paulo, Brasil: Lech Livraria Editora Ciencias Humanas.

Moerman, M. (1991). Talking Culture. Ethnography and Conversation Analysis. Pennsylvania: University of Pennsylvania Press.

Malesevic, S. (2004). The Sociology of Ethnicity. London, UK: Sage Publications.

170 Si Somos Americanos. Revista de Estudios Transfronterizos 
Morales, M, González, J. (2011). Tendencias electorales de los grupos indígenas en Chile. EURE 110, 133-157.

Poblete, D. (2010). Movimientos y organizaciones políticas y sociales del pueblo aymara: el caso de Arica-Parinacota y Tarapacá, Chile. Tesis doctoral, Universidad Complutense de Madrid, Madrid, España.

Stavenhagen, R. (1992). Los derechos indígenas: algunos problemas conceptuales. Revista Instituto Interamericano de Derechos Humanos 15, 123-143.

Stavenhagen, R. (1997). Las organizaciones indígenas: actores emergentes en América Latina. En M. Gutierrez (comp.), Identidades étnicas (pp.13-30). Madrid, España: Casa de las Américas.

Sánchez, C. (1999). Los pueblos indígenas: del indigenismo a la autonomía. México: Siglo XXI Editores.

Sariego, J. L. (2002). El indigenismo en la Tarahumara. Identidad, comunidad, relaciones interétnicas y desarrollo en la Sierra de Chihuahua. México: INI, INAH, CONACULTA.

Sen, A. (2008). Identidad y Violencia. La ilusión del destino. Buenos Aires, Argentina: Katz Editores.

Santos, B. (2010). Refundación del Estado en América Latina. Perspectivas desde una epistemología del sur. Lima, Perú: Instituto de Derecho y Sociedad, Programa de Democracia y transformación global.

Tejera, H. (1994). Antropología y Cultura Política en México. En H. Tejera (coord.), Antropología Política: enfoques contemporáneos (pp. 11-35). México: Ed. Plaza y Valdés.

Vargas, M.E. (1994). Educación e ideología. Constitución de una categoría de intermediarios en la comunicación interétnica. El caso de los maestros bilingües tarascos (1964-1982). México: CIESAS, Colección Miguel Otón de Mendizábal.

Vázquez, L. (1992). Ser indio otra vez. La purepechización de los tarascos serranos. México: Consejo Nacional para la Cultura y las Artes.

Vázquez, L. (2010). Multitud y distopía. México: UNAM. 
Van Kessel, J. (1980). Holocausto al progreso: los aymaras de Tarapacá. Ámsterdam, Holanda: Centro de Estudios y Documentación Latinoamericanos.

Wolf, E. R. (1987). Europa y la gente sin historia. México: Fondo de Cultura Económica.

Weber, M. (2002). Economía y Sociedad. México: Fondo de Cultura Económica.

Warman, A. (2003). Los indios mexicanos en el umbral del milenio. México: Fondo de Cultura Económica.

Zárate, J.E. (1993). Los señores de utopía. Zamora, México: COLMICH, CIESAS.

Zapata, C. (comp.). (2007a). Intelectuales indígenas piensan América Latina. Quito, Ecuador: Universidad Andina Simón Bolívar, Editorial Abya Yala, Centro de Estudios Culturales Latinoamericanos de la Universidad de Chile.

Zapata, C. (2007b). Memoria e historia. El proyecto de una identidad colectiva entre los aymara de Chile. Chungara 2, 171-183.

172 Si Somos Americanos. Revista de Estudios Transfronterizos 